\title{
Plan and Conduct a Nursing Staff Development Programme
}

\author{
Ajithakumari .G ${ }^{1}$, V. Hemavathy ${ }^{2}$ \\ Assistant professor, Sree Balaji College of Nursing, Bharath University
}

Principal, Sree Balaji College of Nursing, Bharath University no: 7, Works Road, Chrompet, Chennai-44, India

\section{Introduction}

Staff development is a process directed towards the personal and professional growth of nurses and other personal while they are employed by a health care agency. Staff development refers to all training and education provided by an employee to improve the occupational and personal knowledge, skills and attitudes of rested of rested employees.

\section{Definition}

\section{Staff Development Programme}

Focus on developing nursing skills knowledge within a comprehensive program that includes orientation in service education, continuing education programs job related counseling.

\section{Need of Staff Development}

1) Staff development activities include training and education needed because social change and scientific advancement cause rapid nursing knowledge and skills.

2) Purpose of staff development program for nurses is to provide the opportunity for nurses to continuity acquire and implement the knowledge skill, attitudes ideals and valued essential for maintenance of high quality of nursing care.

3) Education should be transmitted to bring cultural change.

4) Staff education include all planned education activity recognized by a health care agency as directed towards meeting the job related learning needs of the nurse continuing education and in-service education.

\section{Staff Development Activity}

Staff development activities are defined by its concepts such as competence, interest needs leaning and training.

\section{Competence}

Is the state of processing qualities and abilities that are required for a normal role a task (eg) nurse competence in handling new equipment.

\section{Interests}

Are inclinations that cause an individual $t$ be attracted or repelled by certain objects, events are persons with the result that the individual seeks experience that favor development. The goal of staff development program should be stimulate sufficient interest is a topic that the learner will continue to study the object independently.

\section{Need}

Is a lack, tension, desire condemned that implies a person to specific behavior. An educational need is a measurable discrepancy between a person's actual job competence and designed competence level.

\section{Learning}

Consists of desirable behavioral from a proscribed experience.

\section{Training}

May be defined as an method of ensuring that people have knowledge and skills for a specific purpose that they acquired the necessary knowledge to perform the duties of the job. It is expected to acquiring new skills will increases productivity or create a better product.

\section{Philosophy}

The department of continuing education an integral part of the nursing division and embraces the philosophy of the division.

1) We believe that the primary goal of health care agency is the acquirement of a high quality of health care attainment of this goal is confinement of the continues development of all the personal.

2) We believe that the focus of the department of continuing education is the development of all employees including the nurses employed by the health care agency and the nursing community at large.

3) We believe the educational activities should be designed and implemented to promote a high standard of state, effective nursing practice ad increase job enhancement through lifelong learners.

4) We believe that are education environment should be non threatening and acknowledge the individuality of its learners.

5) We believe that teaching decreasing is a dynamic collaborative should process between teacher and learner. The process an result is a change is cognitive, psychomotor and effective behavior of the individual.

6) We believe that mastery learning assist learners is achieving a acceptable level of performance and should be utilized to provide a basis for accountability to the client, to the instructions and the profession of nursing.

7) We believe that nursing service, $n$ nursing education and nursing research must collaborate to effectively 


\section{International Journal of Science and Research (IJSR) \\ ISSN (Online): 2319-7064}

Index Copernicus Value (2013): 6.14 | Impact Factor (2014): 5.611

solve problems and to facilitate the nursing divisional goal attainment.

\section{Staff Development Model for Goal Achievement of the Health Care Agency the Nurse and the Nursing Profession}

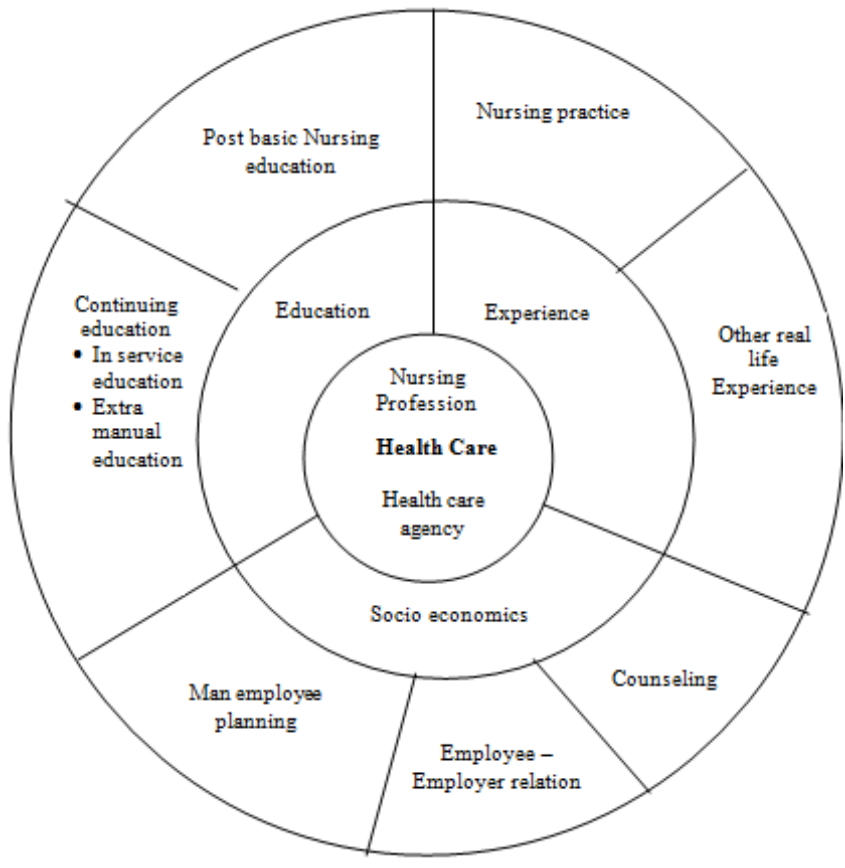

Functions of Staff Development Program:

1) To provide educational activities for all nurses employed by the health care agency directed towards change behavior related to role expectations.

2) The staff development program must be concerned with the growth and development of personal from their critical contact with a health care agency until termination of service.

3) Staff development can be facilitated within an agency and can be provide a linkage with per service education, experience and socio economics of the nurse.

\section{Socio-Economics}

1) Manpower planning - Recruitment selection placement

2) Counseling - Prformance evaluation career planning promoting

3) Employee relation - Personal policies and practices Health services, Lab our relation

\section{Experience}

\section{Nursing Practices:}

Direct patient care general or specialties as independent patient care assignment or team approach.

Indirect patient care supervision admonitions teaching and research
Other real life experiences:

- Colleague interaction

- Voluntary activities related to health care

- Professional associates participates

- Personal life

\section{Education}

\section{(i) Continuing Education}

- In-service education

- Orientation

- Skills attitude knowledge patient to nursing practice with the health care team and to career planning for indirect nurse practitioner

- Extra moral education pertinent to individual health care agency

\section{(ii) Post Basic Nursing Education}

It is pertinent to nursing practice individual and health care agency.

The broadest sense, staff development has 3 major components - education. It begins with orientation to the health care agency and to a particular position and continues in the form of specific skill training related to nursing more generalized skill training related to patient care.

Outside the agency the nurse educational activities may continue as extra moral education or as post basic education. Extra mural education like in-service education can rightly be classified as continuing education.

\section{Types of Staff Development:}

Staff development includes formal and informal group and individual training and education the goals of staff development programmers is her or his present position and to acquire personal and professional absolute is that maximize the possibly of carrier advancement

\section{Induction Training:}

It is a brief standized indoctrination to an agency's philosophy, purpose, policies and regulations gives to each worker during her first two or three days of employment is order to ensure his or her identification with agencies philosophy goals and norms.

\section{Job Orientation}

Orientation training programme introduces new employee to these basic aspects of her job. In the hospital field of any new nurses are appointed first the sparser has to discuss with them the job chart, Policies, procedures and fulfillment of objectives, standing orders policies of institution orientation skill training has to be given for development of knowledge and skills. 


\section{International Journal of Science and Research (IJSR) \\ ISSN (Online): 2319-7064}

Index Copernicus Value (2013): 6.14 | Impact Factor (2014): 5.611

\section{Inservice Education:}

It refers to an ongoing on the job instruction that is give to enhance the workers performance in their present job. Inservice education is a pleasured educational experience provided in the job setting and closely identified with service in order to help the person to perform more effectively as a person and a worker.

\section{Aims}

- Improvement of client through up grading the services reduced with scientific principles.

- To keep in face changing society to their needs

- Acquisition of new knowledge

- Improvement of performance

- To develop right concept of client care

- To maintain the high standards of nursing

\section{Continuing Education}

Continuing education of health workers include the experiences after initial training which help healthcare personnel to maintain and improve existing and acquire new competencies.

Continuing education is all the learning activities that occurs after an individual has completed his basic education

\section{Administrative Structure of Staff Development Programme}

The major factors that determine the administration structure of an agency wide staff development programme are:

- Administration philosophy, policies and practice of health care agency

- Policies and practices and standards of nursing and other health professions

- Human and material resources within a health care agency

- Physical facilities within a health care agency and the community

- Financial resources with a health care agency and the community

\section{Roles and Functions of Administrator / Manager in Staff Development}

Roles

- Applies adult learning principles when helping employees learn new status

- Coaches employees readily regarding knowledge and skill deficits

- Activity seeks out teaching opportunities

- Uses teaching techniques that empower staff

- Is section to the learning defects of the staff

- Frequent assess learning needs of the unit

\section{Functions}

- Works in reduction departments to delicate should individual responsibility for staff development

- Ensure that are the adequate resources for staff development

- Assumes responsibility for quality and fiscal control of staff development activity

- Makes appropriate decision regarding educational resources allocation in fiscal constraints

- Ensures that all stage are competent for roles assigned provides input in formulating staff development policies

\section{References}

[1] C.M. Prasad. "Principles \& Practice of Management" $6^{\text {th }}$ edition, 2004, Sultan Chand \& Sons Publication Page No. $214-18$.

[2] Chabra, 2003 "Principles Practice of Management", $8^{\text {th }}$ Edition; Darpar Rai and Co., New Delhi.

[3] Francis, C.M. Soyza,M. C. de, (2000) "Hospital Administration" $3^{\text {rd }}$ edition, Jaypee Brothers, New Delhi - $270-281$.

[4] Heinz Weitrich and Harold Knootz, "Management" $10^{\text {th }}$ edition. Mc Graw Hill Publication - Page No. 519 -602 .

[5] Jawahar Lal, "Cost Management", 5 $5^{\text {th }}$ edition, Mc Graw, Hill publication page - 519-602.

[6] Jha. S.M. 2005 "Hospital Management" Ist edition: Himalaya Publishing House, Mumbai. Pg. 344 - 368 